\title{
INITIAL DEPRESSION AND NORMALIZATION OF HIGHER EXTREMITY OXYGENATION IN AN AUTISTIC GIRL DUE TO KINESITHERAPY USING AN ADAPTED HIGH ALTITUDE PROTECTION SUIT: A CASE STUDY
}

\author{
Maciej ABAKUMOW', Stefan P. GAŹDZIŃSKI², Krzysztof KOWALCZUK³ \\ ${ }^{1}$ Neures Poland, Warsaw, Poland \\ ${ }^{2}$ Creative Neuroscience Lab - CNS Lab, Military Institute of Aviation Medicine, Warsaw, Poland \\ ${ }^{3}$ Department of Simulator Studies and Aeromedical Training, Military Institute of Aviation Medicine, \\ Warsaw, Poland
}

Source of support: Own sources

Author's address: M. Abakumow, Neures Polska, Przasnyska 6a Street, 01-755 Warsaw, Poland, e-mail: rehabilitacja@neures.pl

Introduction: Autism spectrum disorder is often accompanied by motor impairments that can be treated with kinesitherapy. At Neures Poland, we use high-altitude compensation suits (R-WUK) to help stabilize patients. Here, we report on a case of very low oxygenation of peripheral tissue (hands) in a fifteen-year-old girl $(52 \mathrm{~kg}, 165 \mathrm{~cm}$ ) with a diagnosis of autism. That oxygenation normalized during kinesiotherapy utilizing the R-WUK over the period of two months.

Methods: Before the commencement of therapeutic sessions, the patient's vital signs and tissue oxygen saturation $\left(\mathrm{SpO}_{2}\right)$ in upper extremities were measured. These measurements were repeated before and following the rest of the therapeutic sessions.

Results: Before the sessions, $\mathrm{SpO}_{2}$ was $74 \%$, while the other measures were in the normal range. Over the first month of therapy, $\mathrm{SpO}_{2}$ was low, but after sessions, it was higher, except for the first session in the normal range. $\mathrm{SpO}_{2}$ remained normal before and after the sessions following a seven-week break in the therapy.

Conclusions: R-WUK caused an equalization of saturation levels at the distal level in the upper limbs. Understanding the mechanisms requires further research.

Keywords: high altitude protection suit, psychiatric disorder, autism spectrum disorder, physiology 


\section{INTRODUCTION}

Our search for new solutions in the field of physiotherapy equipment has focused on height compensatory clothing. Its mechanism consists in the administration of increased pressure in the tubing that causes shrinkage of the fabric on muscle structures. The principle of operation points to the concept of increasing prioperceptive sensation, which would allow accelerating the rehabilitation process, especially in patients with neurological deficits or neurological diseases.

Altered motor behavior is commonly reported in Autism Spectrum Disorder [1]. At Neures Polska (www.neures.pl), we started using high-altitude compensation suits (R-WUK) to help stabilize patients during kinesiotherapy, similar to an earlier Russian experience [3]. The mechanisms of R-WUK in some regards resemble the mechanism of hyperbaric therapy, which is used to treat patients with Autism Spectrum Disorder [2,5,6], although its use is not recommended as a treatment method [4].

In the presented study we used an adapted version of high-altitude compensations protection suits (R-WUK (WUK-90, Air-Pol, Legionowo, Poland). It is a capstan-type suit. In this system, compression over the body is achieved through inflating rubber tubes, which increase the pressure on the body with non-distending tapes sewn into the suit's fabric. In addition, the suit is equipped with an abdominal bladder exerting pressure on the lower abdomen and the frontal pelvic region. Precise adjustment of the suit is done with the use of polypropylene laces. Closing of the suit is achieved by means of metal zippers. Here, we report a case of improvements of finger-tissue oxygenation that accompanied the therapy.

\section{MATERIAL AND METHODS}

A fifteen year old girl $(52 \mathrm{~kg}, 165 \mathrm{~cm})$ with a diagnosis of autism and attending a special school for mentally challenged children underwent 16 kinesiotherapy sessions divided into two blocks (see table 1 and table 3) with an R-WUK, similarly to [3]. The sessions were seven weeks apart. The disease was preceded by a strong incident at the age of 2.5 years, the direct cause of which was the appearance of siblings in the family. The girl reacted with strong crying and screaming, which lasted many hours. As a result of this event, the mental development of the patient was completely inhibited. The patient is in full verbal contact with the parents. The study protocol was approved in advance by Bioethical Committee of the Military
Institute of Aviation Medicine in Warsaw (decision no. 3/2017). The parents of the patient provided a written informed consent before the study.

Before and after each kinesiotherapy block, the patient's systolic and diastolic blood pressure was measured (with OMRON ${ }^{\mathrm{TM}} \mathrm{M} 2$ BASIC blood pressure monitor, OMRON Healthcare, Wegalaan 67-69, 2132 JD Hoofddorp, The Netherlands). Arterial blood saturation $\mathrm{SpO}_{2}$ was measured twice each time with the use of a finger pulse oximeter Nonin Medical Model 8500 M (Nonin Medical, Inc., Tilburg, The Netherlands). Mean blood oxygenation (both oxygenated and de-oxygenated blood) of the frontal lobe of the brain was measured using near infrared spectroscopy (NIRS; INVOX 5200 (INVOX Medical, Vocali, Spain)). An optode was attached to the forehead of the patient. These parameters were measured before and after each training session.

\section{RESULTS}

An improvement has been observed in the form of greater cooperation between the patient and therapists, as well as less aggressive reactions. This behavior was present even if the patient was dissatisfied that she had to follow orders.

Systolic blood pressure before the training (SBP1) and after the training (SBP2), diastolic blood pressure before (DBP1) and after (DBP2) each session, heart rate before (HR1) and after (HR2), as well as peripheral oxygen saturation before $\left(\mathrm{SpO}_{2}\right.$ 1) and after $\left(\mathrm{SpO}_{2}-2\right)$ each session are presented in table 1. Please note that the $\mathrm{SpO}_{2}$ before the first session was $74 \%$. Normal blood oxygen levels in humans is considered to amount to 95-100 percent. If the level is below 90 percent, it is considered low, resulting in hypoxemia. Blood oxygen levels below 80 percent may compromise organ function, such as the brain and heart, and should be promptly addressed. (https://en.m.wikipedia. org/wiki/Oxygen_saturation_(medicine)). However, the patient had no typical symptoms of hypoxia of tissue structures such as pallor, bruising or seizures.

It is worth noting that the low saturation result was last recorded by the investigators at the ninth therapeutic unit, but in the eighth one full oxygen saturation was recorded.

The first result $\left(\mathrm{SpO}_{2}=74 \%\right)$ was at first treated as a measurement device error or a measurement error, but in the case of subsequent sessions, when the result was significantly abnormal, daily home monitoring was commissioned to observe $\mathrm{SpO}_{2}$. The results obtained during home observa- 
tion are presented in table 2 . Brain saturation was measured only during the 9th session of the first therapeutic block, after normalization of peripheral saturation, and was normal.

Tab. 1. Vital signs and oxygenation changes with consecutive therapeutic sessions: Systolic blood pressure before (SBP1) and after trainings (SBP2), diastolic blood pressure before (DBP1) and after (DBP2) sessions, heart rate before (HR1) and after (HR2), as well as peripheral oxygen saturation before $\left(\mathrm{SpO}_{2}-1\right)$ and after $\left(\mathrm{SpO}_{2}-2\right)$ sessions.

\begin{tabular}{lccccccccc}
\hline Session No: & 1st & 2nd & 3rd & 4th & 5th & 6th & 7th & 8th & 9th \\
\hline $\mathrm{SPO}_{2}-1$ & 74 & - & 79 & 99 & 80 & - & 96 & 100 & 83 \\
\hline $\mathrm{SPO}_{2}-2$ & 84 & - & 97 & 99 & 92 & - & 98 & 99 & 96 \\
\hline $\mathrm{SBP} 1$ & 115 & 116 & 120 & 119 & 118 & 119 & 126 & 119 & 120 \\
\hline $\mathrm{DBP} 1$ & 71 & 64 & 65 & 62 & 68 & 64 & 71 & 63 & 66 \\
\hline $\mathrm{SBP} 2$ & 124 & 95 & 116 & 122 & 116 & 105 & 135 & 124 & 119 \\
\hline $\mathrm{DBP} 2$ & 63 & 52 & 61 & 63 & 57 & 69 & 75 & 63 & 64 \\
\hline $\mathrm{HR} 1$ & 49 & 69 & 72 & 80 & 66 & 99 & 79 & 79 & 95 \\
\hline $\mathrm{HR} 2$ & 87 & 70 & 71 & 75 & 64 & 75 & 82 & 69 & 66 \\
\hline
\end{tabular}

Tab. 2. Blood saturation at home. Missing values due to lack of collaboration of the patient. *- reading before therapy unit.

\begin{tabular}{lcccc}
\hline & 1st day & 2nd day & 3rd day & 4th day \\
\hline Morning 6.00- 7.30 & - & 97 & 97 & 98 \\
\hline Afternoon 14.00-16.00 & - & 90 & 99 & 97 \\
\hline Evening 21.00-22.30 & 98 & 89 & - & 80 \\
\hline
\end{tabular}

Tab. 3. Vital signs and oxygenation changes during the second block of therapy seven weeks after the first block: Systolic blood pressure before (SBP2-1) and after trainings (SBP2-2), diastolic blood pressure before (DBP1) and after (DBP2) sessions, heart rate before (HR1) and after (HR2), as well as peripheral oxygen saturation before $\left(\mathrm{SpO}_{2}-1\right)$ and after $\left(\mathrm{SpO}_{2}-2\right)$ sessions.

\begin{tabular}{lccccccc}
\hline Session No: & 1st & 2nd & 3rd & 4th & 5th & 6th & 7th \\
\hline $\mathrm{SPO}_{2}-1$ & 97 & 99 & 98 & 99 & 97 & 99 & 97 \\
\hline $\mathrm{SPO}_{2}-2$ & 99 & 99 & - & 98 & 99 & 99 & 99 \\
\hline $\mathrm{SBP} 1$ & 116 & 124 & 104 & 105 & 127 & 116 & 116 \\
\hline $\mathrm{DBP} 1$ & 63 & 61 & 57 & 60 & 70 & 65 & 60 \\
\hline $\mathrm{SBP} 2$ & 124 & 124 & - & 120 & 129 & 129 & 121 \\
\hline $\mathrm{DBP} 2$ & 66 & 61 & - & 61 & 71 & 72 & 62 \\
\hline $\mathrm{HR} 1$ & 81 & 82 & 88 & 86 & 90 & 89 & 90 \\
\hline $\mathrm{HR} 2$ & 85 & 84 & - & 90 & 90 & 88 & 85 \\
\hline & & & & & & &
\end{tabular}

\section{AUTHORS' DECLARATION:}

Study Design: Maciej Abakumow, Krzysztof Kowalczuk. Data Collection: Maciej Abakumow, Krzysztof Kowalczuk. Manuscript preparation: Maciej Abakumow, Stefan Gaździński, Krzysztof Kowalczuk. The Authors declare that there is no conflict of interest.

We have observed severely depressed $\mathrm{SpO}_{2}$ in a 15 year old girl diagnosed with autism, that was reversed after a few sessions of kinesitherapy with an adapted high-altitude protection suit (R-WUK). These changes were persistent.

$\mathrm{O}_{2}$ saturation disturbances are observed in chronic lung diseases, asthma or mountain diseases. In chronic diseases, the adaptive mechanism of the body allows one to reduce the oxygen saturation of $\mathrm{HBO}_{2}$ to the level of $80 \%$, but at the expense of the efficiency of the human body - movements are sluggish and slowed down. In addition, not always is the state of consciousness of the patient full and the level of perception and logical thinking in these conditions is significantly reduced. The above-mentioned symptoms of hypoxia are similar to autistic symptoms such as motor slowdown, disorders resulting from the function of receptors and the desire to restore them, lack of reaction, etc. Therefore, low tissue oxygenation may partially account for the symptoms of autism.

The results of research on the use of R-WUK suits adapted for therapeutic purposes suggest that the suit does not only affect the mechanism associated with prioperception, but also includes a much larger spectrum of physical interactions, which translate into the physiology of the body and define their area not only to patients with neurological diseases but also mental diseases.

Furthermore, the reading of the pulse oximeter are mostly affected by blood oxygenation in the capillary vessels, in which the device directly carries out measurements. These results may indicate that the original, low blood saturation in the finger of the patient is related to small blood vessels, such as arterioles and capillaries, and the action of the R-WUK suit modifies the blood arterioles restoring normal blood flow. 


\section{REFERENCES}

1. Gowen E, Hamilton A. Motor Abilities in Autism: A Review Using a Computational Context. Journal of Autism and Developmental Disorders. 2013; 43(2):323-44.

2. Halepoto DM, Al-Ayadhi LY, Salam AaA. Therapeutic Use of Hyperbaric Oxygen Therapy for Children with Autism Spectrum Disorder. Jcpsp-Journal of the College of Physicians and Surgeons Pakistan. 2014; 24(7):508-14.

3. Kogan OG, Naydin V. Medical rehabilitation in neurology and neurosurgery. Medicina. 1988.

4. Mathieu D, Marroni A, Kot J. Tenth European Consensus Conference on Hyperbaric Medicine: recommendations for accepted and non-accepted clinical indications and practice of hyperbaric oxygen treatment (vol 47, pg 24, 2017). Diving and Hyperbaric Medicine. 2017; 47(2):131-2.

5. Rossignol DA. Hyperbaric Oxygen Treatment in Autism Spectrum Disorders. In: DietrichMuszalska A, Chauhan V, Grignon S, editors. Studies on Psychiatric Disorders. Oxidative Stress in Applied Basic Research and Clinical Practice. 2015; 553-66.

6. Rossignol DA, Rossignol LW, Smith S, Schneider C, Logerquist S, Usman A, et al. Hyperbaric treatment for children with autism: a multicenter, randomized, double-blind, controlled trial. Bmc Pediatrics. 2009; 9.

Cite this article as: Abakumow M, Gaździński SP, Kowalczuk K. Initial Depression and Normalization of Higher Extremity Oxygenation in An Autistic Girl Due to Kinesitherapy Using An Adapted High Altitude Protection Suit: A Case Study. Pol J Aviat Med Bioeng Psychol 2018; 24(3): 19-22. DOI: 10.13174/pjambp.11.02.2020.03 